\title{
Pulmonary hernia after thoracoscopy: case report
}

\author{
Joseph Lula Lukadi ${ }^{1}$, Dominique Gossot ${ }^{1}$, Agathe Seguin-Givelet ${ }^{1,2}$ \\ ${ }^{1}$ Thoracic Surgery Department, Curie-Montsouris Thoracic Institute, Paris, France; ${ }^{2}$ Paris 13 University, Sorbonne Paris cité, Faculty of Medicine \\ SMBH, Bobigny, France \\ Correspondence to: Agathe Seguin-Givelet. Institut Mutualiste Montsouris, 42 Bd Jourdan, F-75014 Paris, France. Email: agathe.seguin-givelet@imm.fr.
}

\begin{abstract}
Pulmonary hernia is a rare medical condition with an old history that dates back to the XV century. About a half of cases have been reported after trauma. The pulmonary hernia is also known as a complication of open thoracic surgery. Although it has been reported after closed chest surgery, it seems to be underreported. We report four cases of pulmonary hernia after minor or major thoracoscopic procedures. We present clinical data of patients and discuss clinical features and prevention of this adverse effect of thoracoscopic surgery. Three patients were symptomatic, a painful bulge increasing with chest strain at the specimen extraction incision scar, and they were operated on. The diagnostic of pulmonary hernia is not always straightforward at clinical examination which is the milestone of the diagnostic. Computed tomography (CT) scan can mislead, especially when it is not performed under the Valsalva maneuver. The pulmonary hernia following thoracoscopy is treated like other hernias. The peculiarity of the pulmonary hernia following the video-assisted thoracoscopic surgery (VATS) would be, the hernia orifice is often a tiny opening, that is a theoretical risk of pulmonary strangulation; its anterior inferior location is a risk of possible enlargement of the hernia to the abdomen. For these 2 reasons some would directly operate almost each pulmonary hernia after thoracoscopy. We think that, only symptomatic patients with either persistent or worsening symptoms should have a surgical repair. The postoperative outcome is uneventful. More care is expected in the diagnostic phase. The pulmonary hernia should be discussed as differential diagnostic for a patient who has been operated on after a thoracoscopy with lingering parietal symptoms, especially pain.
\end{abstract}

Keywords: Case report; thoracoscopy; lung; herniation; complication

Received: 22 April 2021; Accepted: 20 June 2021; Published: 30 December 2021.

doi: $10.21037 /$ asj-21-19

View this article at: https://dx.doi.org/10.21037/asj-21-19

\section{Introduction}

Pulmonary hernia is a well-known condition. Several cases have been reported after open surgery (1). Although thoracoscopic and video-assisted thoracic procedures aim at preserving the chest wall, some specific parietal complications can occur (2). One of these, is postoperative pulmonary herniation, an underreported side effect. We report, 4 cases of pulmonary herniation following thoracoscopy. We present these cases in accordance with the CARE reporting checklist (available at https://asj. amegroups.com/article/view/10.21037/asj-21-19/rc).

\section{Cases presentation}

From 2007 to 2020, 1,860 full thoracoscopic minor and major resection have been performed, in our department, thoracic surgery, Curie-Montsouris Institute. These were prospectively recorded in our database (CEPAR 2012-010). Out of the postoperative complications, we have noticed 4 cases of pulmonary herniation whose data have been analyzed.

We have observed 4 postoperative pulmonary hernias after thoracoscopy. The patients average age was 66.7 years (range, 57-76 years), there were 3 female patients. They were operated on for suspicion of a non-small cell lung cancer (even if one ended up to bear a benign lesion). All patients were overweight with an average body mass index (BMI) of $27.5 \mathrm{~kg} / \mathrm{m}^{2}\left(26.8-28.3 \mathrm{~kg} / \mathrm{m}^{2}\right)$. Three of them presented with chronic obstructive pulmonary disease (COPD) and the other one suffered from asthma. Three of 

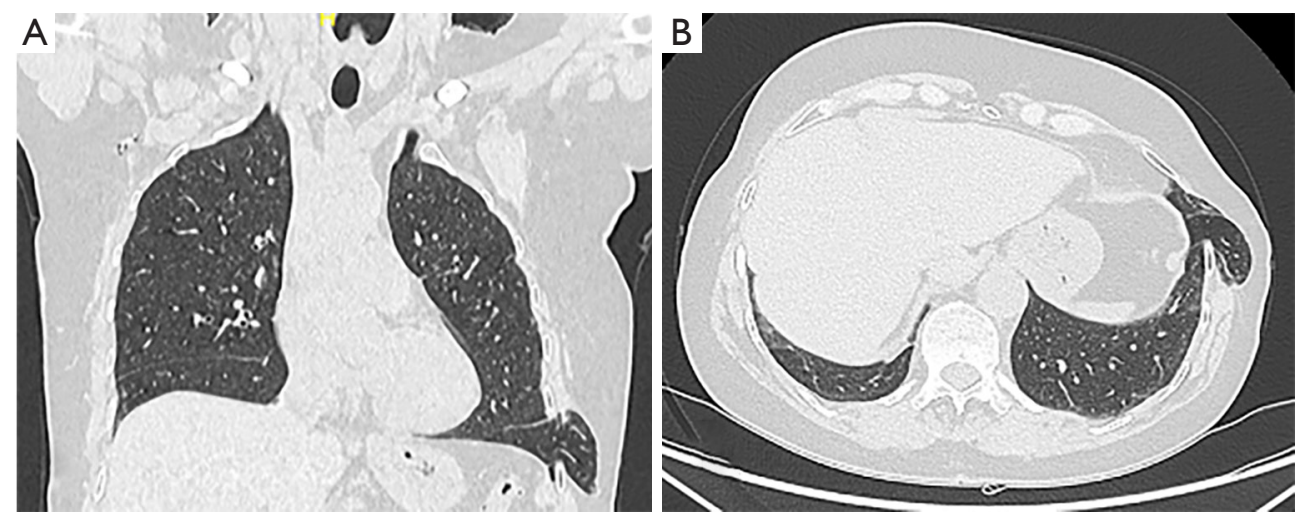

Figure 1 A huge pulmonary bulge ( $6^{\text {th }}$ intercostal space) on a 68-year-old woman chest CT scan after a lingular wedge resection. (A) Coronal view; (B) axial view. CT, computed tomography.

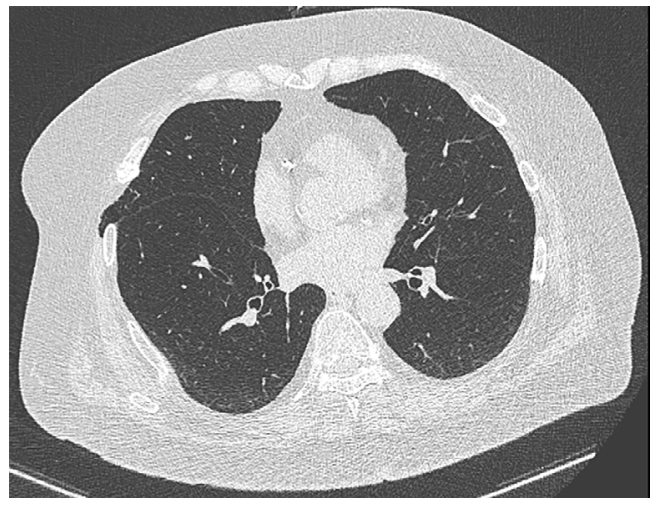

Figure 2 A noticeable parietal pleural discontinuity with a subsequent lung protrusion ( $5^{\text {th }}$ intercostal space) on a 76-year-old woman chest CT scan with asymptomatic lung hernia after a right apical and posterior segmentectomy. CT, computed tomography.

the patients were symptomatic. An asymptomatic 76-yearold woman is under observation.

The hernias were localized on the anterior and inferior port that was used for the specimen extraction, pertained to the $5^{\text {th }}, 6^{\text {th }}, 7^{\text {th }}$ intercostal spaces. The hernia was noticed within several months, with a median of 11 months (0.513 months) after thoracoscopy. However, one case was diagnosed 15 days after a left wedge resection.

All four patients presented with an underlying medical condition, 3 of them had a chronic obstructive pulmonary disease (COPD); the other one suffered from asthma, sleep apnea syndrome, and bore a chest radiotherapy history. On 3 patients, hernia was obvious at clinical examination, with a renitent and painful mass, at the site of the specimen extraction scar incision. The bulge was increasing with coughing.

The diagnosis was confirmed by computerized tomography (CT) scan (on 2 patients: Figures 1,2) that demonstrated lung parenchyma protruding through the intercostal space. The 2 other CT scans were considered normal.

The diagnostic was not often obvious; a chronic neurological post thoracoscopy pain, a pulmonary embolism were discussed as differential diagnostics.

The three symptomatic patients were reoperated upon 2 months after the hernia was diagnosed.

An elective mini thoracotomy was performed along the previous scar, the muscular layer was unraveled at all the patients, the ribs were spread, but a rib spreader was not used, all the 3 patients presented with the hernial sac of different size (that was resected after being dissected), there was no strangulation, the adherences were present and there were easily freed. The lung was reduced within the chest cavity, we used rib periosteal wires at a patient (after applying the patch). The Gore-Tex mesh $(10.0 \mathrm{~cm} \times 15.0 \mathrm{~cm}$ $\times 2.0 \mathrm{~mm}$ GORE-TEX Soft Tissue Patch, W.L. Gore \& Associates. Inc, Newark, Delaware, USA) was anchored to the adjacent ribs in an intrapleural position. We carefully closed the muscles and subcutaneous tissues separately. The operation lasted on average 88 minutes (64-121 minutes). The postoperative course was uneventful in all 3 patients who were discharged 2 to 3 days after the procedure with no recurrence to date, throughout an overall (median) of 14 months (6-105 months) surveillance. The asymptomatic, unoperated patient is still followed up (for 15 months, to date).

Demographics, clinical characteristics, CT findings 
Table 1 Patient's demographics, clinical characteristics, CT findings and therapeutic attitude

\begin{tabular}{|c|c|c|c|c|c|c|c|c|}
\hline Patient & Sex & Age & $\mathrm{BMI}$ & Specimen & Comorbidity & Clinical signs & CT findings & Attitude \\
\hline 2 & $\mathrm{~F}$ & 67 & 27.6 & Culmen & COPD & Severe & Absent & Operation \\
\hline 3 & $M$ & 57 & 27.6 & ML & COPD & Evident & Absent & Operation \\
\hline 4 & $\mathrm{~F}$ & 76 & 28.3 & $\mathrm{R} \mathrm{S1+2}$ & COPD & Absent & Slight & Surveillance \\
\hline
\end{tabular}

BMI, body mass index; ULL wedge, wedge of upper left lobe; SAS, sleep apnea syndrome; ML, middle lobe; COPD, chronic obstructive pulmonary disease; CT, computed tomography.

and according therapeutic attitudes of each patient are summarized in Table 1.

All procedures performed in this study were in accordance with the ethical standards of the institutional and national research committee and with the Helsinki Declaration (as revised in 2013). Written informed consent was obtained from all patients for publication of this case report and accompanying images. A copy of the written consent is available for review by the editorial office of this journal.

\section{Discussion}

Pulmonary herniation commonly occurs after a trauma. It is also a rare complication of open surgery; less than 10 cases have been reported. Pulmonary herniation has been described following open and minimally invasive cardiac surgery, after lung transplantation, even after general thoracic surgery, especially after anterior thoracotomy or mediastinotomy (1). With respect to thoracoscopy, the incidence of this complication is unknown. We have found only 19 cases (3-8) in PubMed from 1997 to 2018. Some have been reported after video-assisted thoracoscopic surgery (VATS) lobectomy and even after pleuroscopy $(4,6)$. However, this complication might be underreported. Even though, we did find 4 cases in our series, we are aware that we may have missed some patients who were lost for followup, this means there are probably more cases.

Thoracoscopy may favor pulmonary hernias. The main reason is probably that the surgeon is reluctant to tightly close the intercostal space port used for specimen retrieval, precisely because the procedure is supposed to be minimally invasive with the aim of lowering pain as much as possible.

The 4 cases we have observed, occurred in patients operated on by our technique of full thoracoscopy, where no utility incision was used, the chest tube is set away from the extraction port (2). Only, the most anterior and inferior port was slightly enlarged according to specimen size. The most clinically and early expressive patient presented a normal CT scan. This highlights how CT scan can be misleading. The patient, with the boldest CT expression, underwent a wedge resection. This underlines the fact that the length of the incision (or the specimen size) might not be the issue.

Several authors point out the following factors on patients with the postoperative pulmonary herniation: obesity, COPD, subcutaneous emphysema following the primary operation, avulsion of the costal cartilage, intensive intercostal muscles cauterization, insufficient soft tissues dissection, the previous use of the steroids, no closing each layer separately (8).

Our patients were overweight, with an underlying pulmonary condition (most of the time, COPD), the subcutaneous emphysema can be identified on some of their postoperative $\mathrm{X}$-rays (of the primary operations).

With regard to prevention, local checking of the specimen extraction intercostal space, followed by a thorough anatomical closing of the smooth tissues is important.

Placing a chest tube through this incision should be avoided so that incision closure keeps as tight as possible.

\section{Conclusions}

Pulmonary hernia is most likely an underestimated complication of VATS. Its diagnostic is not always obvious, but it is easy to treat. Prevention is based on thorough port closure, especially in overweight patients and/or those with COPD. Placing a chest tube through the specimen extraction incision should be avoided to not weaken it. Finally, for patients at risk, a regular visit, several months after discharge, to check the integrity of the chest wall may be advisable.

\section{Acknowledgments}

Funding: None. 


\section{Footnote}

Reporting Checklist: The authors have completed the CARE reporting checklist. Available at https://asj.amegroups.com/ article/view/10.21037/asj-21-19/rc

Peer Review File: Available at https://asj.amegroups.com/ article/view/10.21037/asj-21-19/prf

Conflicts of Interest: All authors have completed the ICMJE uniform disclosure form (available at https://asj.amegroups. com/article/view/10.21037/asj-21-19/coif). DG reports that he is a consultant at Delacroix-Chevalier and has been a lecturer for Metronic and Olympus. ASG reports that she is a consultant for AstraZeneca and she has been a lecturer for Medtronic. The other author has no conflicts of interest to declare.

Ethical Statement: The authors are accountable for all aspects of the work in ensuring that questions related to the accuracy or integrity of any part of the work are appropriately investigated and resolved. All procedures performed in this study were in accordance with the ethical standards of the institutional and/or national research committee(s) and with the Helsinki Declaration (as revised in 2013). Written informed consent was obtained from all patients for publication of this case report and accompanying images. A copy of the written consent is available for review by the editorial office of this journal.

Open Access Statement: This is an Open Access article distributed in accordance with the Creative Commons Attribution-NonCommercial-NoDerivs 4.0 International License (CC BY-NC-ND 4.0), which permits the noncommercial replication and distribution of the article with

doi: $10.21037 / \mathrm{asj}-21-19$

Cite this article as: Lula Lukadi J, Gossot D, Seguin-Givelet A. Pulmonary hernia after thoracoscopy: case report. AME Surg J 2021;1:28. the strict proviso that no changes or edits are made and the original work is properly cited (including links to both the formal publication through the relevant DOI and the license). See: https://creativecommons.org/licenses/by-nc-nd/4.0/.

\section{References}

1. Mhamdi S, Aouini I, Daboussi S, et al. Intercostal lung herniation secondary to thoracotomy: a case report. Pan Afr Med J 2020;36:39.

2. Gossot D. Atlas of Endoscopic Major Pulmonary Resections. Cham: Springer International Publishing; 2018.

3. Haro A, Komiya K, Taguchi Y. A rare case of an intercostal lung herniation with fractures of the fifth and sixth ribs after thoracic surgery. Int J Surg Case Rep 2017;41:473-6.

4. Batıhan G, Yaldız D, Ceylan K. A rare complication of video-assisted thoracoscopic surgery: lung herniation retrospective case series of three patients and review of the literature. Wideochir Inne Tech Maloinwazyjne 2020;15:215-9.

5. Hauser M, Weder W, Largiadèr F, et al. Lung herniation through a postthoracoscopy chest wall defect: demonstration with spiral CT. Chest 1997;112:558-60.

6. Ishibashi H, Hirose M, Ohta S. Lung hernia after videoassisted thoracoscopic lobectomy clearly visualized by three-dimensional computed tomography. Eur J Cardiothorac Surg 2007;31:938-938.

7. Ema T, Funai K, Kawase A et al. Incarceration hernia of the lung after video-assisted thoracic surgery requiring emergency operation: a case report. J Thorac Dis 2018;10:E541-3.

8. Athanassiadi K, Bagaev E, Simon A et al. Lung herniation: a rare complication in minimally invasive cardiothoracic surgery. Eur J Cardiothorac Surg 2008;33:774-6. 